\title{
Speech Acts in a Dialogue Game Formalisation of Critical Discussion
}

\author{
Jacky Visser ${ }^{1}$
}

Published online: 10 June 2016

(c) The Author(s) 2016. This article is published with open access at Springerlink.com

\begin{abstract}
In this paper a dialogue game for critical discussion is developed. The dialogue game is a formalisation of the ideal discussion model that is central to the pragma-dialectical theory of argumentation. The formalisation is intended as a preparatory step to facilitate the development of computational tools to support the pragma-dialectical study of argumentation. An important dimension of the pragmadialectical discussion model is the role played by speech acts. The central issue addressed in this paper is how the speech act perspective can be accommodated in the formalisation as a dialogue game. The starting point is an existing 'basic' dialogue game for critical discussion, in which speech acts are not addressed. The speech act perspective is introduced into the dialogue game by changing the rules that govern the moves that can be made and the commitments that these result in, while the rules for the beginning, for the end, and for the structure of the dialogue game remain unchanged. The revision of the move rules is based on the distribution of speech acts in the pragma-dialectical discussion model. The revision of the commitment rules is based on the felicity conditions that are associated with those speech acts.
\end{abstract}

Keywords Critical discussion · Dialogue games · Formalisation · Pragmadialectics $\cdot$ Speech acts

The present paper is a revised and extended version of a paper presented at the European Conference on Argumentation (Visser 2016).

Jacky Visser

j.c.visser@uva.nl

1 Speech Communication, Argumentation Theory, and Rhetoric, University of Amsterdam, Spuistraat 134, 1012VB Amsterdam, The Netherlands 


\section{Introduction}

Computational methods are becoming increasingly important in the study and teaching of argumentation. The use of computational support tools opens up research opportunities in argumentation studies that would not exist otherwise. A good example of such a new opportunity is the use of computer programs for argument mining (cf. Lippi and Torroni 2015) to do quantitative studies into the argumentative content of large corpora, at a speed human analysts can only dream of. In the teaching of argumentative skills as well, the addition of e-learning modules to existing educational methods can be of great benefit (cf. Scheuer et al. 2010).

One of the main contemporary theories used in the study and teaching of argumentation, is the pragma-dialectical theory developed by van Eemeren and Grootendorst (1984, 1992, 2004; van Eemeren 2010; van Eemeren et al. 2014, pp. 517-613) and their co-authors. Despite the increasing impact of computational methods on the field of argumentation theory in general, the pragma-dialectical theory has so far not been part of these new developments. To start changing this, a first preparatory step is made by formalising the discussion model that is at the core of the pragma-dialectical theory; the ideal model of a critical discussion. This formal preparation is meant to simplify the subsequent development of computational applications on a pragma-dialectical basis.

Existing formalisations of the discussion model (e.g. Krabbe 2013; Visser 2015a) have focussed primarily on the dialectical dimension of the model-the critical norms of reasonableness - neglecting its pragmatic dimension-a speech act perspective on communication. In the current paper, the focus is widened to explore the pragmatic dimension, thereby bringing the formalisation closer to the full scope of the ideal model. How this speech act perspective can be accommodated in a formalisation of the discussion model, is the main topic addressed in this paper. In Sect. 2, I will discuss the goal of formalisation in preparation of computational application. In Sect. 3, I will introduce the incremental development of a dialogue game as formalisation of the discussion model. In Sect. 4, I will explain how the speech act perspective that is inherent in the discussion model is accommodated in the formalisation. In Sect. 5, I will specify the rules of a dialogue game for critical discussion taking into account the speech act perspective.

\section{Formalisation in Preparation of Computerisation}

In his 2014 keynote address opening the eighth conference of the International Society for the Study of Argumentation (ISSA), Frans van Eemeren (2015a) mentioned formalisation as one of the most important current topics in argumentation research. Formalisation can serve several purposes in argumentation theory. Most obviously perhaps, it can be seen as a next step in the development of a theory. Through formalisation, concepts and relations are defined very precisely, and models can be verified with mathematical means. This function of formal models 
has been described by Krabbe and others (e.g., Krabbe 2006, pp. 195-197; Krabbe and Walton 2011, pp. 256-259) as an 'abstract theoretical laboratory'. The 'laboratory' makes it possible, for example, to 'experimentally' test the instrumental validity of a model, in order to improve it on theoretical grounds. Additionally, formalisation can serve as a preparation for computerisation. The computational implementation of an informal model or theory implies a preparatory formalisation. Through formalisation, the concepts and 'language' of the theory are brought closer to the formal language inherent in computer programming. This last purpose of formalisation is the primary objective of this paper.

The computational application of argumentation theory has enjoyed an increasing amount of attention over the last decade, not only from argumentation theorists, but also within the research field of Artificial Intelligence. Overviews of the state of the field, such as the chapter 'Argumentation and Artificial Intelligence' in the Handbook of Argumentation theory (van Eemeren et al. 2014, pp. 615-675), and the volume Argumentation in Artificial Intelligence edited by Rahwan and Simari (2009), show the broad spectrum of computational applications of argumentation theoretical notions and insights. Aside from the aforementioned e-learning and argument mining, there are, for example, computer programs to support legal practitioners in constructing and evaluating legal cases (e.g., Verheij 2005), medical applications where argumentation is used to improve the computerised distribution of donor organs (e.g., Tolchinsky et al. 2008), software programs to draw diagrams of argumentation structures (e.g., Gordon 2010), and online repositories of analytically annotated argumentative texts (e.g., Bex et al. 2013).

Although various computational support tools could be of value to the pragmadialectician, one of the most exciting is the automated analysis of texts. Existing approaches to argument mining allow the automated reconstruction of argumentative structures in large corpora of texts (e.g. Budzynska et al. 2014), but at the current stage of development, the resulting reconstructions are less elaborate and precise than the analyses of human scholars. Furthermore, to be a useful addition to the pragma-dialectician's analytical toolbox, support software should use pragmadialectical concepts and theoretical starting points, which is currently not the case. This second issue can be addressed by basing argument mining software on the pragma-dialectical method of analysis (which may additionally lead to progress on the first issue).

The foundation of the pragma-dialectical method of analysis (van Eemeren and Grootendorst 1992; van Eemeren et al. 1993; van Eemeren 2010) is the ideal model of a critical discussion. Based on a critical conception of reasonableness (van Eemeren and Grootendorst 2004, pp. 16-17), the discussion model is a proposal for an ideal procedure for the resolution of differences of opinion in a reasonable way (ibid., pp. 42-68). The procedure is specified by means of fifteen 'technical' rules 
for critical discussion (ibid., pp. 135-157), representing the 'dialectical dimension' of critical discussion. ${ }^{1}$ The 'pragmatic dimension' consists of an amended integration of a Searlean speech act perspective on language use and a Gricean conception of communicative interaction (van Eemeren and Grootendorst 1992, pp. 49-55). ${ }^{2}$

Inspired by the later Wittgenstein's (1953) shift towards the study of meaning in action, Speech Act Theory (Austin 1962; Searle 1969) considers communication to not merely consist of the use of truth-conditional statements, but rather of performing dialogical actions with the potential of changing (communicative) reality. The basic idea is that of doing things with words: acting through speech. Speech acts are analysed in terms of their communicative force-what act is performed-and their propositional content-what the act is about. Examples of stereotypical speech acts are giving advice, issuing a warning, making a promise, giving orders.

An amended version of Speech Act Theory (van Eemeren and Grootendorst 1984, pp. 19-46), integrated with a Gricean conception of cooperation in communicative events (1992, pp. 49-55), plays an important role in the pragmadialectical theory. Discussion moves are realised by means of speech acts in a critical discussion (van Eemeren and Grootendorst 2004, p. 62), and the speech act perspective is essential in the reconstruction of the so-called 'unexpressed premises' that constitute the justificatory force of argumentation (van Eemeren and Grootendorst 1984, pp. 119-149). Because the speech act perspective is an inherent part of the ideal model of a critical discussion, it should also be accounted for in a formalisation of that model. Before turning to the accommodation of the speech act perspective, I will introduce the general idea of a formalisation.

\section{A Dialogue Game as Formalisation of Critical Discussion}

The formalisation of critical discussion is developed as a dialogue game. A dialogue game is a formal rule system, defining a set of dialogues that can be 'played out'. The rules of the game determine which moves can be made by which player, at which moment and to which effect on the developing dialogue. Additionally, the rules state the goal of the dialogue and when this goal is realised. An elaboration on the later Wittgenstein's (1953) goal-driven and isolated 'language games', systems of formal dialectic and dialogue games have been employed by philosophers to study the dynamics of reasoning and dialogue (e.g., Hamblin 1971; Lorenzen and Lorenz 1978; Walton and Krabbe 1995). Based on these philosophical studies,

\footnotetext{
1 The fifteen Rules should not be confused with the ten 'practical' commandments for reasonable discussants (van Eemeren and Grootendorst 1992, pp. 208-209), which are intended as practical rules of thumb for conducting, analysing and evaluating argumentative discussions. To distinguish the fifteen Rules of the ideal model from the rules of the dialogue game (Sect. 5), they are referred to as 'Rules' with a capitalised ' $R$ '.

2 The pragmatic dimension should not be mistaken for one aimed at practical reasoning or actionoriented decision-making. In the sense intended here, 'pragmatic' refers to the traditional distinction within linguistics between syntax, semantics and pragmatics (cf. Levinson 1983).
} 
dialogue games are now also commonly used in Artificial Intelligence to model dialogue and communication in multi-agent systems (cf. Norman et al. 2004; McBurney and Parsons 2009; Prakken 2009).

The dialogue formalisation of critical discussion that is developed in this paper, is intended to be 'formal' in three senses. First, the formalised model has to be procedurally regimented (formal 3 in the taxonomy by Barth and Krabbe 1982, pp. 14-19; Krabbe 1982) and a priori or normative (formal 4 , or 'formal' as Hamblin (1970, p. 256) contrasts it to descriptive models which are based on empirical observation). Krabbe and others (Krabbe and Walton 2011, p. 246; Krabbe 2012, p. 12; van Eemeren et al. 2014, p. 304) have noted that the existing pragmadialectical ideal model is already formal in these two senses. Additionally, the dialogue game should be formal in a third sense, in which the original ideal model is not formal: the rigid definition of well-formed linguistic expressions and the way in which these can be combined (formal 2 ).

An earlier proposal to formalise the ideal model of a critical discussion by Krabbe (2012, 2013), has the same objective: making the system formal 2 . While Krabbe's approach and his resulting dialogue system $\mathrm{CD}_{1}$ are very insightful (and forms a valuable point of departure for my own formalisation), I believe the formalisation can stay closer to the original ideal model. As Krabbe (2013, pp. 240-241) already acknowledges, his formalisation diverges from the original ideal model in several respects. First-and foremost within the context of the present paper-Krabbe's formalisation deals with the dialectical dimension of the ideal model, at the expense of the role of speech acts. Second, $\mathrm{CD}_{1}$ allows for series of moves, instead of enforcing a strict turn-based procedure. Third, in the case of argumentation with a complex propositional content, the elementary propositions are attacked one by one. It is my intention that the dialogue game developed in this paper: (1) also incorporates the pragmatic dimension of critical discussion, (2) adheres to strict turn-taking, and (3) allows the casting of doubt on the complete propositional content of argumentation in one move.

Krabbe mentions a fourth way in which his $\mathrm{CD}_{1}$ would diverge from the ideal model: by interpreting intersubjective procedures as means of defence for the protagonist. Contrary to Krabbe's concern, in this respect $\mathrm{CD}_{1}$ appears to be in line with what van Eemeren and Grootendorst say with respect to the intersubjective identification procedure (and which they reassert for the other procedures): "This method of defence on the part of the protagonist therefore consist of a joint check being carried out at his request" (1984, p. 166, emphasis added).

In the concluding section of this paper, I will evaluate whether my proposal manages to stay closer to the ideal model in these respects than Krabbe's. In any case, differences in some properties and aspects between the formalisation and the ideal model are unavoidable and to be expected. The divergence could be the result of the streamlining inherent to the formalisation of informal models: the expressiveness of formalisms is usually more limited than that of natural language. Formal models have to be fully explicit and free of ambiguity to define what is part of the model and what is excluded. This restricted expressiveness means that the formalisation is stricter than the original ideal model. However, if the formalisation yields a result that diverges from the original ideal model, this could also be an 
indication of an imperfection or obscurity in the original model (cf. the laboratory function mentioned in Sect. 2).

My formalisation of critical discussion is not developed in its entirety in one go. Instead, a dialogue game is systematically built up, starting from a simplified basis to which additional features are gradually added by extending and changing the dialogue game rules. In this step-by-step fashion, the dialogue game increasingly does justice to the full scope of features of the ideal model. This incremental approach has the practical advantage of decomposing a large task into many smaller constitutive tasks, which can be carried out at different times and by different people. A second advantage [also mentioned by Krabbe (2013, p. 241)] is of a theoretical nature: by gradually increasing the complexity of the dialogue game, the properties of the model can be studied in isolation from other features of the model that may otherwise complicate the investigation (cf. the 'laboratory function' of formal models mentioned in Sect. 2).

The foundation of the incremental development is made up by the basic dialogue game for critical discussion (Visser 2015a, b). The scope of the basic formalisation is restricted to represent only a simplified core of features of the ideal model of a critical discussion. Based on these restrictions, the dialogue game is defined through five categories of rules. There are rules for the initial state of the game (see also Sect. 5.1), for the available moves (see also Sect. 5.2), for the commitments that moves result in (see also Sect. 5.3), for the possible sequences of moves (see also Sect. 5.4), and for the way in which the game ends (see also Sect. 5.5). ${ }^{3}$

The first important simplification of the basic dialogue game with respect to the ideal model is its aforementioned restriction to the dialectical dimension. While the pragmatic dimension is attended to in the present paper, the additional 'rhetorical dimension' still remains unattended. Within the pragma-dialectical theory, the rhetorical dimension is concerned with the strategic manoeuvring of discussants and the influence of the institutional context on the discussion (van Eemeren 2010). Analogous to this rhetorical aspect of the effective means of persuasion in communicative activity, players of the dialogue game also have to make choices about their next move. Although the strategies that players employ to improve their chances of winning the dialogue game may be modelled using game theory (e.g., Rahwan and Larson 2009), they are not considered an intrinsic part of the rules of the game itself (cf. Jacobs and Jackson 1982). Rather they have to do with the constitution of the players of the dialogue game, which is not defined by the rules.

In the ideal model, discussants are presumed to be human interlocutors. Because the dialogue game is intended as a preparation for computational application, no such assumption is made here. The dialogue game should be such that in principle both human and artificial agents can play it. Which mechanisms either sort of player employs to internally represent the state of the game, how they determine their strategy, and how they keep track of their own and their opponent's commitments is not specified in the rules of the game. In the case of human agents, their internal

\footnotetext{
${ }^{3}$ With the exception of the commencement rules, this way of specifying a dialogue game follows the 'standard framework' of locution rules, commitment rules, structural rules and win-and-loss rules, albeit with slightly different labels (cf. Walton and Krabbe 1995). The category of commencement rules is also part of McBurney and Parsons' (2009, p. 265) generic framework for the specification of dialogue games.
} 
constitution is a topic for psychologists, and in the case of artificial agents, it is a topic for software engineers. The rules of the dialogue game do not refer to the internal state or beliefs of the players, but only take into account the commitments that the players externalise during the game. ${ }^{4}$

As a further simplification, the dialogue game represents only two of the four discussion stages distinguished in the ideal model: only the argumentation stage and the concluding stage of critical discussion are part of the dialogue game. The confrontation stage, in which the nature of the difference of opinion is externalised, and the opening stage, in which the starting points of the discussion are set, are only accounted for through the assumptions made in the 'commencement rules' for the initial state of the dialogue game.

The exclusion of the confrontation stage, means that the initial situation of the dialogue game is different from existing dialogue games in which the disputed issue still has to be established in the first moves of the game, such as in Mackenzie's (1979) DC or in Rescher's (1977) formal disputations. The assumed outcome of the confrontation stage, as reflected in the commencement rules, is that a single positive standpoint has been advanced and cast doubt on. This simplification constrains the dialogue game to single non-mixed differences of opinion about one positive standpoint, thereby excluding differences of opinion about more than one or about negative standpoints.

The first assumed outcome of the opening stage is that the players agree to only use single argumentation, which may be criticised only by casting doubt, not through contradiction. This means that complex argumentation structures and (potentially mixed) sub-discussions are excluded (see also: Visser 2013). ${ }^{5}$ The second assumption is that the justificatory force of the single argumentation may only be based on the inference rules of classical propositional logic (e.g., modus ponens). This simplifying assumption with respect to the underlying logic does not preclude the later introduction of more complex or nuanced systems into the dialogue game, such as non-monotonic systems for defeasible reasoning (e.g., Pollock 1987; Dung 1995), or the pragma-dialectical argument schemes with accompanying critical questions (van Eemeren and Kruiger 1985; van Eemeren and Grootendorst 1992; Garssen 1997). The assumed simplifying outcomes of the confrontation stage and of the opening stage result in a dialogue game formalisation of the dialectical dimension of the argumentation stage and the concluding stage of a consistently non-mixed discussion about one positive standpoint which is defended with a single justificatory argument. In the remainder of this paper, the addition of the pragmatic dimension is explored.

\footnotetext{
4 This exclusive focus on externalised commitment implements van Eemeren and Grootendorst's (2004, pp. 53-55) meta-theoretical principle of 'externalisation'.

5 Van Eemeren and Grootendorst (1984, pp. 78-83) follow a similar approach in their introduction of the ideal model of a critical discussion, by starting with an elementary discussion from which more complex discussions can be composed.
} 


\section{Accommodating a Speech Act Perspective in the Dialogue Game for Critical Discussion}

Van Eemeren and Grootendorst (1984, pp. 98-112) describe the distribution of different (types of) speech acts over the four stages of the ideal model and give an overview of the functions the speech acts have in critical discussion. In this way, every (dialectical) discussion move in the ideal model is associated with a particular (type of) speech act prototypically used to realise it. These associated speech acts form the basis for the extension of the dialogue game rules.

Taking account of the speech act perspective will mainly affect two of the five categories of dialogue game rules. In comparison to the existing basic dialogue game, the rules for the initial state of the game (Sect. 5.1), for the possible sequences of moves (Sect. 5.4), and for ending the game (Sect. 5.5) remain largely unchanged. The amendments to the 'move rules' (Sect. 5.2) reflect the speech acts that are associated with the realisation of discussion moves in the ideal model. Paraphrases in natural language are added to each move as well. The 'commitment rules' (Sect. 5.3) reflect the relevant felicity conditions of the associated speech acts.

Every speech act comes with a number of conditions that should be fulfilled for the speech act to be performed felicitously, the 'felicity conditions' (Searle 1969; van Eemeren and Grootendorst 1984, pp. 19-46). According to van Eemeren and Grootendorst (1992, p. 50), listeners can, in ordinary situations, assume a speaker to "be clear, honest, efficient and to the point" (the 'Communication Principle'). This leads to a speaker's commitment that the felicity conditions of the speech act he performs are expected to be fulfilled. As van Eemeren and Grootendorst (1992, p. 30) explain: "The listener is entitled to assume that a speaker who has asked a question is interested in the answer, that a speaker who has made an assertion is convinced that this assertion is true, that a speaker who has promised something really intends to do it, and so forth."

There can nevertheless be a discrepancy between the speaker's and the listener's perspective on the status of the felicity conditions (van Eemeren and Grootendorst 1989). If the listener has doubt regarding the fulfilment of a condition, this can give rise to a difference of opinion. In this way, the felicity conditions of speech acts contribute to the 'disagreement space', the collection of potentially contentious propositions in a dialogue (van Eemeren et al. 1993, pp. 102-104). If the fulfilment of a felicity condition is indeed disputed by the listener, the speaker should justify his presumption that the felicity condition could be considered to be fulfilled (cf. Jackson 1992, p. 260). The propositional content of the standpoint of which the acceptability is at issue in the resulting difference of opinion consists of a proposition expressing the fulfilment of the felicity condition under consideration (cf. van Eemeren and Grootendorst 1984, pp. 95-98; Houtlosser 1995, pp. 65-91; van Eemeren 2015b, pp. 331-345). In the dialogue game such propositions expressing the fulfilment of felicity conditions will be used to represent the 
commitments that players acquire as the result of making a move (see Sect. 5.3). ${ }^{6}$

Van Eemeren and Grootendorst (1984, pp. 95-118, 2004, p. 68) explain that, in the argumentation stage, speech acts of the class of assertives are used to advance argumentation (technically constituting an illocutionary act complex), commissives are used to accept or reject argumentation, and directives are used to request additional argumentation. In the concluding stage, assertives are used to maintain or retract standpoints, and commissives are used to accept or reject standpoints. In all stages of a critical discussion, discussants can also request and perform usage declaratives to ask for or provide clarification, explication, disambiguation, etc. (van Eemeren and Grootendorst 1984, pp. 109-110). While usage declaratives can contribute to the resolution of differences of opinion, there are no moves in the dialogue game representing these speech acts. The dialogue game is such that all moves are fully explicit to begin with, under the assumption that it is also clear what propositions refer to (see Sect. 3). This obviates the need for usage declaratives. Although in principle it is possible to incorporate usage declaratives and requests for such, this would severely affect the dynamics of the game, making the sequential structure less clear. How the other speech acts are represented in the dialogue game formalisation is explained in the next section.

\section{The Extended Rules of the Dialogue Game for Critical Discussion}

Before turning to the dialogue game rules, a preliminary assumption is made about the way the rules can express what the discussion is about. The rules assume there to be some formal propositional language $\mathscr{L}$ that can be used to express the content of moves and of commitments in the dialogue game. Because the particular composition of $\mathscr{L}$ is not the main concern in the current study, no formal definition of $\mathscr{L}$ will be provided. It should be sufficient to think of $\mathscr{L}$ as a propositional language consisting of (an infinite number of) propositions, two connectives, $\Rightarrow$ and $\&$, and the auxiliary symbols (and). The propositions can be considered to refer to (atomic or molecular) sentences of classical propositional logic (i.e., $\mathscr{L}$ can be thought of as a meta-language 'about' propositional logic).

The first connective, $\&$, can be used to conjoin two propositions of $\mathscr{L}$. The second connective, $\Rightarrow$, composes two propositions $A, B \in \mathscr{L}$ into $A \Rightarrow B$ (to be read as " $A$ therefore $B$ "). $A \Rightarrow B$ expressed the justificatory force of the first proposition for the second: claiming that $B$ may be inferred from $A$ in the reasoning system (or logic) which $\mathscr{L}$ is a meta-language of. The assumption of propositional logic (see Sect. 3) as the underlying system means that any use of $A \Rightarrow B$ can be interpreted as denoting the application of some propositional rule of inference to the effect that the acceptability of $A$ justifies the acceptability of $B$. Without going into detail about specific rules of inference, it is sufficient to assume there to be some methods, external to the dialogue game, which the players can call on to determine

\footnotetext{
6 The conception of felicity conditions in terms of propositions that speakers become committed to is also conveyed by others. According to Jackson (1985, p. 128), for example: "the performance of any [speech] act is seen as committing the speaker, in principle to the ... felicity conditions ..., expressible as propositions".
} 
the acceptability of propositions and inferences in the dialogue game. ${ }^{7}$ The external methods are assumed to return a definitive positive or negative outcome.

Propositional identity is restricted to each of the rules that follow-in other words, only within the scope of each rule it holds that $A=A$; it is not the case that the $A$ in the first rule, $\mathrm{B} 1$, has to refer to the same proposition as the $A$ in the last rule, T1; the letter is just a placeholder. Furthermore, within each rule any two different placeholders represent different propositions - in other words, within one rule it holds that $A \neq B \neq C$. Finally, to justify the adequacy of the proposed formalisation, reference will often be made to van Eemeren and Grootendorst's (2004) book A systematic theory of argumentation. To keep the text more readable and concise, these references shall be abbreviated to 'vEG 2004' with the relevant page number.

\subsection{Beginning the Dialogue Game}

The commencement rules determine the initial state of the game before the first move is made. Because the confrontation stage and the opening stage of critical discussion are not explicitly modelled here, the outcomes of these stages are taken to be part of the initial state of the dialogue game. Based on the assumed outcome of the confrontation stage the dialogue game is played by two players to assess the tenability of one positive standpoint. The propositional content of the standpoint is specified in rule B1 as the initial expressed opinion (van Eemeren and Grootendorst 1984, p. 89). The expressed opinion, according to van Eemeren and Grootendorst (1984, p. 5), "may refer to facts or ideas [...] actions, attitudes, and so on", and can therefore be any proposition of $\mathscr{L}$ (thereby also adhering to Rule 1 of the ideal model (vEG 2004, p. 136) which ensures that there are no special conditions for standpoints).

B1 initial_expressed_opinion $=A \in \mathscr{L}$

Based on the first of the assumed outcomes of the opening stage, the two players are labelled Prot and Ant in rule B2. ${ }^{8}$ These labels match the division of discussion roles of respectively protagonist and antagonist that discussants agree upon in the opening stage of critical discussion [cf. Rule 4 of the ideal model (vEG 2004, p. 142)]. The protagonist player, Prot, defends a positive standpoint with respect to the initial expressed opinion in the argumentation stage, whereas the antagonist player, Ant, critically assesses this defence in view of her doubt about the initial expressed opinion.

B2 Players $=\{$ Prot, Ant $\}$

\footnotetext{
7 The external methods are closely related to the intersubjective identification, inference and testing procedures of the ideal model (van Eemeren and Grootendorst 2004, pp. 145-150).

${ }^{8}$ For the sake of clarity, player Prot will be referred to with male pronouns, and Ant with female pronouns (following the standard way of referring to proponents and opponents in the literature on formal dialectics and dialogue logic).
} 
A second outcome of the opening stage is the agreement on a set of mutually acceptable material and procedural starting points. In the dialogue game B3 represents the material starting points as a (static) set $S P$ of propositions that are considered acceptable by both players. Because critical discussants need at least one shared material starting point to have a meaningful discussion (vEG2004, p. 139), $S P$ is taken to be non-empty.

B3 $S P \neq \varnothing$

The procedural starting points are, for the moment, included in the dialogue game as three meta-principles. These principles supersede all the particular rules of the dialogue game and can be considered as higher order rules. First, perhaps obviously, the players have to play by the rules of the game-in other words: cheating is not possible [in line with Rule 5 of the ideal model (vEG2004, p. 143)]. Second, the game is turn-based. This means that players take turns in which they must make exactly one move and then pass the turn to the other player, who subsequently does the same [following Rule 13 of the ideal model (vEG2004, p. 154)]. Third, the players have agreed upon some specific reasoning system (for example propositional logic) and an accompanying method to check the acceptability of inferences appealed to [cf. Rules 5 and 8 of the ideal model (vEG2004, pp. 143-150)].

Finally, the goal of the dialogue game has to be clear: resolving a difference of opinion about a positive standpoint with respect to some proposition, through Prot's advance of argumentation in defence of the acceptability of that proposition, and Ant's critical reaction to the argumentation. Unsurprisingly, this goal is very similar to that of (the argumentation stage of) critical discussion (cf. vEG2004, p. 61).

\subsection{Moves}

The moves players can make are of the form type( $p$, "Paraphrase", $A)$ or type ( $p$, "Paraphrase", $A, B$ ), where type indicates the function of the move, $p \in$ Players denotes the player making the move, Paraphrase is a description of the move in natural language, and $A, B \in \mathscr{L}$ is the propositional content of the move. In the rules that follow-M1 to M8-all but one of the moves refer to one proposition, which can be atomic or in some cases molecular. One of the moves (M1) makes reference to two propositions. In accordance with Rule 13a of the ideal model (vEG2004, p. 154), which prohibits the repetition of speech acts, every unique instantiation of a move can only occur once per game. This means that no specific combination of the elements that make up a move may be repeated during the course of one game.

The different type's of the moves are based on the speech acts that play a role in critical discussion and on the dialectical requirements of the fifteen Rules of critical discussion. For example, the type of the move in rule M1, argue, is a representation of the speech act complex 'argumentation' in the ideal model, and the type of the move in rule M5, doubt, represents the illocutionary negation of an assertive used to indicate non-acceptance in the ideal model.

The Paraphrase's of the moves are standardised utterances that uniquely identify the moves, without using the fully explicit (technical) form. They are inspired by the 
'standard paraphrases' that van Eemeren and Grootendorst (1984, pp. 112-118) introduced for the speech acts relevant to critical discussion. Besides clarifying the function of a move, the Paraphrase's may facilitate natural language interfaces, should the dialogue game be implemented in a computer system.

The dialogue game for critical discussion is asymmetrical with respect to the roles of the two players (cf. vEG2004, p. 142). This results in there being three sets of moves: one for each of the players, depending on their role, and there is one move that is available to both players. Player Prot has the moves in rules M1-M5 at his exclusive disposal to defend his standpoint, and Ant makes exclusive use of M6 and M7. Both players can use move M8.

The first move is perhaps the quintessential move of the dialogue game. By means of M1, Prot can put forward argumentation in support of the initial_expressed_opinion at issue, in accordance with Rule 6a (vEG2004, p. 144). This is where it becomes relevant that $A \neq B$. To prevent circular reasoning, Prot may not instantiate both $A$ and $B$ with the initial_expressed_opinion. Otherwise, the standpoint would support itself.

M1 argue(Prot, "My argument for ... is ...", $A, B$ )

To defend his argumentation, Prot can use M2 and M3 to initiate respectively the agreed upon intersubjective identification procedure to assess the acceptability of the propositional content of his argumentation, or the intersubjective testing procedure to assess the acceptability of the justificatory force. These moves are based on Rules 7a (vEG2004, p. 147) and 8a (vEG2004, p. 150) of the ideal model. Even though the intersubjective procedures are performed mutually by the two players, they are assumed to be initiated by Prot (cf. van Eemeren and Grootendorst 1984, pp. 166-169).

M2 identify(Prot, "I invoke the intersubjective identification procedure to verify the acceptability of ...", A)

M3 test(Prot, "I invoke the intersubjective testing procedure to verify the acceptability of ...", $A \Rightarrow B$ )

When his argumentation or standpoint turns out to be untenable, Prot can use M4 to retract his commitment to it. It is important to note that the object of the retraction is not the earlier move, because what has been said cannot be 'unsaid': once made, a move stays on the record. In other words, the dialogue game is cumulative with respect to moves (cf. Woods and Walton 1978). What is retracted, is a proposition, $A$, to the effect of the player giving up his commitment to the acceptability thereof (see Sect. 5.3). The explicit retraction of his argumentation by Prot is an addition in the dialogue game that is not based on a direct corollary speech act in the ideal model. The move has been added to accommodate the right to retract argumen- 
tation, as guaranteed by Rule 12 of the ideal model (vEG2004, p. 153). ${ }^{9}$ The possibility to retract a standpoint is necessary because of Rule 14a (vEG2004, p. 154) that requires the retraction of standpoints that have been conclusively attacked.

M4 retract(Prot, "I am no longer of the opinion that ...", A)

Contrary to a retraction, Prot can use a maintain-move M5 to maintain his standpoint after a conclusive defence thereof. According to Rule 9a of the ideal model (vEG2004, p. 151), a standpoint is conclusively defended if the acceptability of the propositional content and the acceptability of the justificatory force of the argumentation have been successfully defended. The maintain-move is also Prot's way of transitioning from the argumentation stage to the concluding stage, as is also shown in the dialectical profile of the concluding stage of a critical discussion (van Eemeren et al. 2007, pp. 224-225).

M5

maintain(Prot, “I maintain my standpoint with respect to ...”, A)

To critically test Prot's defence of the standpoint, player Ant can use the moves in rules M6, M7 and M8. According to M6, Ant can cast doubt on the acceptability of the propositional content or the justificatory force of an argument, a right awarded to her on the basis of Rule 10 (vEG2004, p. 152) of the ideal model. If the propositional content of the doubt-move is made up of the initial_expressed_opinion, then the doubt-move also serves as counterpart to Prot's maintain-move and progresses the discussion to the concluding stage, this time in Ant's favour.

M6 doubt(Ant, "I doubt whether ... is acceptable", A)

According to van Eemeren and Grootendorst (2004, p. 143), the antagonist also has to be able to retract doubt about, and thereby accept, argumentation or standpoints [see Rule 14b (vEG2004, p. 154)]. This accept-move is handled by rule M7.

M7 accept(Ant, "I accept that ...", A)

Available to both players, move M8 accounts for Rules 7 and 8 (vEG2004, pp. 147-150) of the ideal model. These Rules concern the successful defence and attack of, respectively, the propositional content and the justificatory force of the argumentation. The propositional content is successfully defended if the intersubjective identification procedure yields a positive result (Rule 7a) and successfully attacked otherwise (Rule 7b). The justificatory force is successfully defended if the intersubjective testing procedure yields a positive result (Rule 8a), and successfully attacked otherwise (Rule 8b). Prot can request Ant to resolve a positive outcome of an intersubjective procedure (cf. the preliminaries at the beginning of Sect. 5) by

\footnotetext{
9 In Sect. 5.4, another advantage of the addition of the explicit retraction of the argumentation will become clear. Making this move explicit circumvents a prima facie conflict between the progression from the argumentation stage to the concluding stage and Rule 13 of the ideal model (vEG2004, p. 154). According to van Eemeren et al. (2007, p. 224) the progression between the stages may result in one discussants making two consecutive discussion moves, while Rule 13 prohibits discussants from making two moves in a row.
} 
accepting the argumentation now that it was successfully defended against an attack. Analogously, in the case of a negative outcome of an intersubjective procedure, Ant can request Prot to resolve the outcome by retracting what was successfully attacked.

M8 resolve( $p$, "I request resolution with respect to ...", A)

\subsection{Commitments}

By making moves, players change the state of the game. As will become clear in Sect. 5.4, every move determines the possible moves the other player can make in the next turn. Additionally, some moves result in certain dialogical commitments for players. These commitments are the positions that players can be held accountable for as a result of the moves they make. The commitments are represented as propositions the acceptability of which a player has to argumentatively defend if prompted to do so (cf. van Eemeren and Grootendorst 1992, p. 38). The propositions players become committed to are kept track of in personal commitment stores (cf. Hamblin 1970, p. 257). The players' commitment stores in the dialogue game take the form of two sets, $C S_{p, t}$, of propositions $A, B, \ldots \in \mathscr{L}$, for player $p \in$ Players, and with an index $t \in \mathbb{N}$ as a turn counter. Every turn the $t$ counters of the commitment stores are increased by one. ${ }^{10}$

Based on the requirements at the beginning of the dialogue game, at $t=0$, Prot's commitment store $C S_{P r o t, 0}$ contains the shared starting points and the propositional content of the standpoint; initial_expressed_opinion $\in \mathscr{L}$. The shared starting points are also contained in $C S_{A n t, 0}$, but initial_expressed_opinion explicitly is nototherwise Ant would already be committed to the proposition under discussion when starting the game, preventing a difference of opinion from arising in the first place. Rules C1 and C2 specify the content of the commitment stores at $t=0$.

$\mathrm{C} 1 \quad C S_{\text {Prot }, 0}=S P \cup\{$ initial_expressed_opinion $\}$

C2 $\quad C S_{\text {Ant }, 0}=S P$

During the game, some of the moves made in a turn $t$ modify the players' commitments. Starting from a speech act perspective makes clear that commitments cannot be equated with moves, but should be treated separately. The moves in the dialogue game are based on the speech acts that are the prototypical realisations of discussion moves, while the commitments are based on the felicity conditions of those speech acts. In contrast to moves, commitments can be retracted (through rules M4 and C4), meaning that while the dialogue game is cumulative with respect to moves, this is not the case with respect to commitments.

\footnotetext{
${ }^{10}$ In the dialogue game, only dialogical commitments of the kind described are taken into account. Action and other commitments, such as obligations to do something in the future, or obligations outside of the discussion, are not taken into account. See Walton and Krabbe (1995) for a more detailed study of commitment.
} 
In principle all dialogue game moves result in a number of commitments covering the felicity conditions of the relevant speech act. Nevertheless, the commitment rules currently only incorporate a small selection of these felicity conditions. This is a deliberate choice in order to keep the rules concise without impacting the game dynamics. Most of the commitments based on the fulfilment of felicity conditions would not play any part in the remainder of the dialogue game, because they are never referred to in the dialogue game rules. They would, on the other hand, cause the commitment stores to become cluttered with irrelevant commitments, making it harder to see how the dialogue progresses. Relevant for inclusion in the dialogue game, then, are only those felicity conditions that create or discharge dialectical obligations within the restrictions posed to the full extent of the ideal model in Sect. 3.

Rules C3, C4 and C5 define the results of the three moves with relevant felicity conditions in terms of the players' commitments. The moves are indicated before the » symbol, with the commitment store changes after it. Moves of the type retract delete a proposition from a commitment store, thereby removing the dialectical obligation to defend it, but potentially also cutting short a line of argumentative defence. Moves of the type accept add commitments, thereby limiting the possibilities of doubt and criticism. Moves of the type argue are based on the argumentation speech act complex, and cause the addition to the commitment store of two propositions expressing respectively the propositional content and the justificatory force of the argumentation (based on the felicity conditions that van Eemeren and Grootendorst (1992, p. 31) describe for the speech act complex). For all the other moves holds that $C S_{p, t}=C S_{p, t-1}$. In the case of a conjunction, the separate conjuncts are added to or deleted from a commitment store (i.e. conjunctions are eliminated prior to operations on the commitment store). To improve the readability, the paraphrases are omitted in the rules that follow.

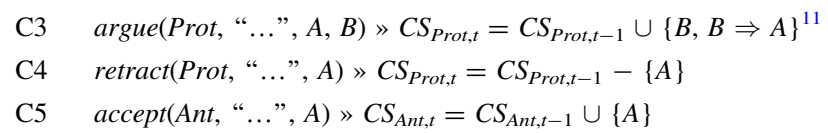

\subsection{Sequences}

The dialogue game always starts with a move argue(Prot, "My argument for ... is ..., $A, B)$ in which Prot advances a proposition $B$ as a reason for the propositional content $A$ of the standpoint at issue. Which subsequent moves may be made, depends on the state of the game at the point when the move is considered. Three properties of the state of the game can be relevant in this respect. The move made in the preceding turn is always of importance. In some cases it is also important what the content of the players' commitment stores is, or what the outcome of an external procedure is, in which case these conditions are also specified in rules $\mathrm{S} 1-\mathrm{S} 8$.

\footnotetext{
11 Because $C S_{\text {Prot, } t}$ and $C S_{A n t, t}$ are not multisets, a proposition can only be a member of the same set once. Any attempt to add a proposition to a commitment store of which it already is a member has no effect.
} 
In the sequence rules, the symbol can be read as 'is a sanctioned continuation of the following moves', meaning that a move before the 4 may be made in reaction to one of the moves following the 4 . The various preceding moves are listed as (a), (b), etc. Because the argue-move is always the opening move of any game, it may always be performed when no preceding move has been made. This is indicated in S1 by a null value.

Some of the sequences are further restricted, indicated in the S-rules by a vertical line: I. After the I, the conditions are listed that have to hold for the sequence of moves to be legal. The colon : is used to indicate a particular substitution of a proposition in a move. For example, according to S7a, a move of the accept-type may be made in response to a move of the argue-type, provided the proposition in the accept-move is substituted with a conjunction of propositions representing the commitments to the propositional content and the justificatory force that result from the argue-move.

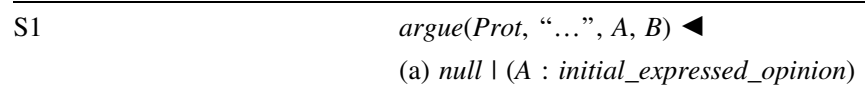

S2

identify (Prot, “...”, A)

(a) $\operatorname{doubt}($ Ant, “...", A) | ((A $\left.\Rightarrow B) \in C S_{\text {Prot }, t}\right)$

S4

test(Prot, “...”, $A \Rightarrow B$ )

(a) $\operatorname{doubt}(A n t$, “...", $A \Rightarrow B)$

retract(Prot, “...”, A)

(a) $\operatorname{doubt}($ Ant, “...", A)

(b) resolve (Ant, “...”, A)

S5

maintain(Prot, “..., A)

S6

(a) $\operatorname{accept}(A n t$, “...”, $B \&(B \Rightarrow A))$

$\operatorname{doubt}($ Ant, “...”, A)

(a) $\operatorname{argue}($ Prot, “...”, $B, A$ )

(b) $\operatorname{argue}($ Prot, “...", $B, C) \mid(A:(C \Rightarrow B))$

(c) resolve(Prot, “...”, B)। $\left((B \Rightarrow C) \in C S_{\text {Prot }, t} ; A:(B \Rightarrow C)\right)$

(d) resolve(Prot, “...”, $A \Rightarrow B$ )

(e) $\operatorname{retract}($ Prot, “...", $B) \mid\left((B \Rightarrow A) \in C S_{\text {Prot }, t}\right)$

(f) $\operatorname{retract}($ Prot, “...”, $B \Rightarrow A$ )

S7

$\operatorname{accept}($ Ant, “...", A)

(a) $\operatorname{argue}(\operatorname{Prot}, “ \ldots ”, B, C) \mid(A:(C \&(C \Rightarrow B)))$

(b) identify (Prot, “...", A)। $(A \in S P)$

(c) $\operatorname{test}($ Prot, “..., $B \Rightarrow C) \mid(B \vdash C ; A:(B \Rightarrow C))^{12}$

(d) resolve (Prot, “...”, $B) \mid\left((B \Rightarrow C) \in C S_{\text {Prot }, i} ; A:(B \&(B \Rightarrow C))\right)$

(e) resolve(Prot, “..., $B \Rightarrow C) \mid(A:(B \&(B \Rightarrow C)))$

(f) $\operatorname{maintain}(\operatorname{Prot}$, “...”, A)

S8

resolve $(p$, “...”, A)

(a) $\operatorname{accept}($ Ant $, \ldots, A) \mid(p:$ Prot $)$

\footnotetext{
12 The turnstile symbol $\vdash$ indicates that $B$ is actually (strictly) derivable from $A$ in classical propositional logic, due to the simplifying assumption from Sect. 3 .
} 

(b) $\operatorname{accept}($ Ant $, \ldots, B \Rightarrow C) \mid(A: B \Rightarrow C ; p:$ Prot $)$
(c) identify(Prot, “...”, A) | $(A \notin S P$; $p:$ Ant $)$
(d) test(Prot, “...", $B \Rightarrow C) \mid(B \nvdash C ; A:(B \Rightarrow C) ; p:$ Ant $)$

The sequential structure of the dialogue game is visualised in Fig. $1{ }^{13}$ The nodes of the graph — the text boxes - represent the dialogue game moves. The edges- the arrows-represent the transitions between moves from one turn of the game to the next. The labels on the edges indicate which sequence rule the transition instantiates. The topmost node of Fig. 1 is the first move of the game (S1): Prot's argumentation (M1). The route straight through the middle is the shortest, where Ant immediately accepts (M7) the argumentative defence of the standpoint (S7a).

The possibility of Ant accepting the argumentation straight away reflects the absence of an obligation in the ideal model of a critical discussion to express criticism with respect to the argumentation provided (vEG2004, p. 151), as long as the argumentation is critically evaluated (vEG2004, p. 61). This latter requirement is met in the dialogue game by means of the interaction between rule S7a and rule C5. The first of these rules ensures that the propositional content of Ant's acceptmove is a conjunction of the propositional content and the justificatory force of Prot's argumentation. The second of the two rules subsequently adds both conjuncts to Ant's commitments, thereby committing Ant to the acceptability of both the propositional content and the justificatory force of the argumentation.

Alternatively to accepting the argumentation, Ant can choose the routes on the left side or on the right side of Fig. 1, by casting doubt (M6) on respectively the propositional content (S6a) or the justificatory force (S6b) of Prot's argumentation. In response to such doubt, Prot can either retract (M4) the propositional content (S4a) or the justificatory force (again S4a, but with a different substitution), or he can initiate (M2 and M3) one of the intersubjective procedure (S2 and S3).

The intersubjective identification procedure is modelled in S7b and S8c as a simple check whether the proposition at hand is part of the set of material common starting points $S P$, an interpretation based on van Eemeren and Grootendorst's explanation (2004, p. 146). In S7c and S8d, the intersubjective testing procedure is modelled as checking whether the initial expressed opinion can indeed be inferred from the propositional content of the argumentation. Depending on the outcome of the procedures, Ant either (S7b/S7c) accepts what she doubted before (M7), or (S8c/ S8d) she requests Prot to resolve the outcome (M8).

If the outcome of the intersubjective procedure was positive and Ant accepted, Prot can react (S8a/S8b) by requesting (M8) Ant to now accept his entire argumentation. Ant can subsequently (S7d/S7e) do so (M7), or, if she did not do so yet, she can shift to the other side of the figure by now casting doubt (M6) on another aspect of the argumentation (S6c/S6d).

\footnotetext{
13 The visualisation is meant to elucidate the dynamics of the dialogue game. Its relation to the pragmadialectical notion of 'dialectical profile', and a reconstruction of a natural language dialogue are provided elsewhere (Visser 2015b).
} 


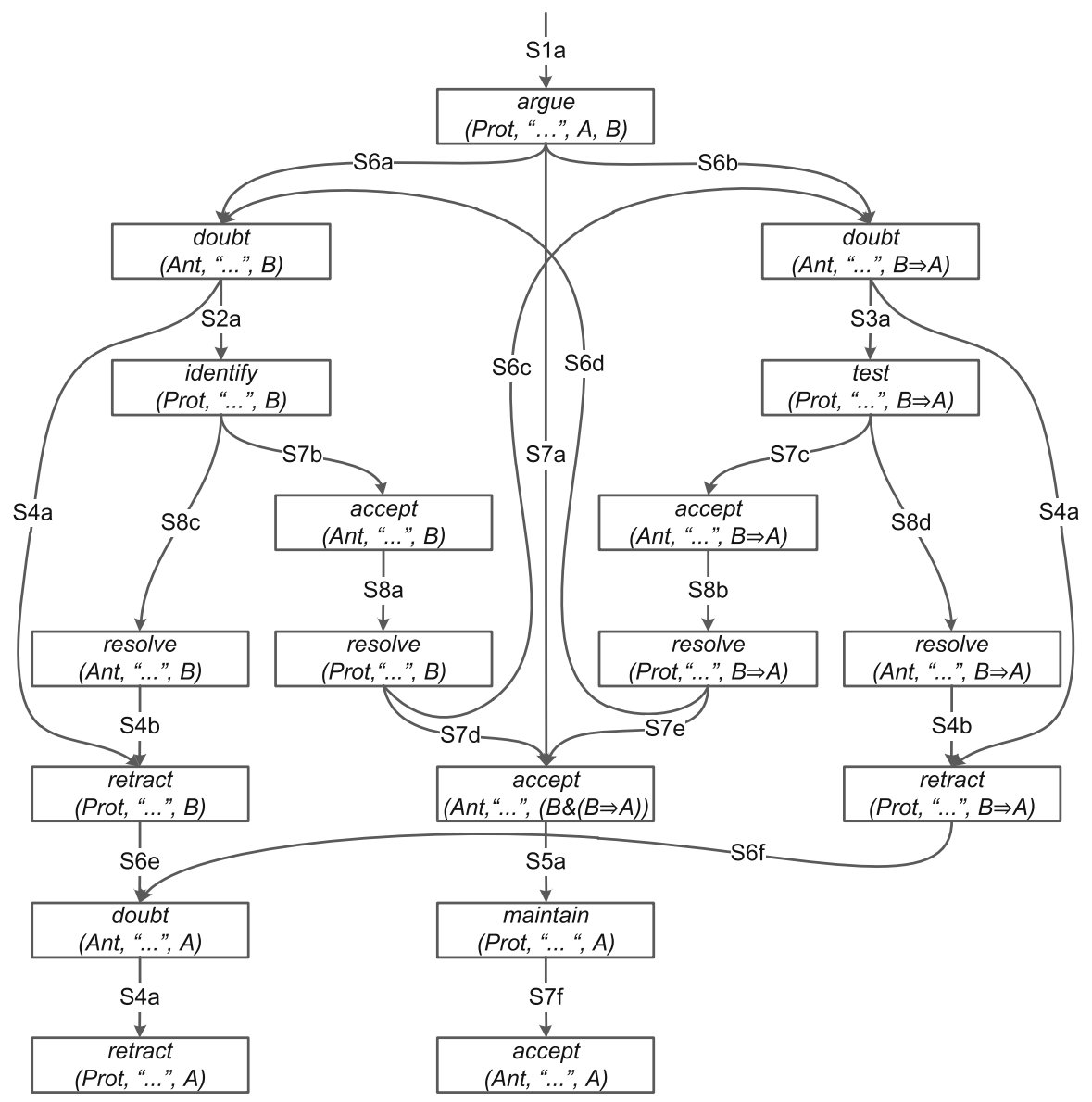

Fig. 1 The sequential structure of the dialogue game for critical discussion

If, on the other hand, the outcome of the earlier intersubjective procedure was negative, and Ant requested resolution, Prot has to retract (M4) the propositional content (S4b) or justificatory force (S4b, with a different substitution) of his argumentation. When this latter situation is the case, or when Ant accepts the entire argumentation, the players may move to the concluding stage by either Prot maintaining (M5) his standpoint (S5), or Ant maintaining her doubt (M6) about it (S6e/S6f). In the first case, Ant is forced to now also accept (M7) the propositional content of the standpoint (S7f). In the second case, Prot is forced to retract (M4) his commitment to the propositional content of the standpoint (S4a). These two terminating moves can be seen at the bottom of Fig. 1.

\subsection{Ending the Dialogue Game}

The dialogue game ends when neither of the players has a way to continue the game in accordance with the rules, resulting in a win for one player and a loss for the 
other. This situation occurs when Ant makes a move to accept the initial expressed opinion or when Prot makes a move to retract his commitment to the initial expressed opinion. Rule 14 of the Rules of the ideal model (vEG2004, p. 154) states that in the concluding stage of critical discussion the protagonist has to retract his standpoint or the antagonist has to retract her doubt on the basis of the outcome of the argumentation stage. In accordance with the concluding stage of the ideal model and in reference to Rule 9 (vEG2004, p. 151), Prot can win the dialogue game by successfully defending both the propositional content and the justificatory force of his argumentation for the standpoint, whereas Ant can win by successfully attacking either the propositional content or the justificatory force.

There are several possible ways of specifying a dialogue game rule that determines who the winner of the dialogue game is. One way is to simply look at which player made the last move. However, in T1, winning and losing are defined on the basis of the players' commitment stores in order to facilitate future extensions of the dialogue game-such as the inclusion of mixed differences of opinion, where both parties can advance argumentation in favour of conflicting standpoints. Termination rule T1 defines that, after making one of the finishing moves in turn $t$, if it is the case that initial_expressed_opinion $\in C S_{A n t, t}$, then Prot wins. In this case, Ant accepted the standpoint about $A$ after a conclusive argumentative defence by Prot. In all other cases Ant wins, because Prot had to retract his commitment to $A$ after a conclusive attack on his single argumentative defence.

$\mathrm{T} 1$

Whenever a move $\operatorname{retract}(p$, “..., $A)$ or $\operatorname{accept}(p$, “...", $A)$ is made in turn $t$, then:

if $A=$ initial_expressed_opinion, then:

if $A \in C S_{\text {Ant, }, \text { winner }}=$ Prot,

otherwise: winner $=$ Ant;

otherwise:

continue playing the game with the next move

\section{Conclusion}

The specified dialogue game is part of a series of dialogue games, systematically geared towards the formalisation of the pragma-dialectical ideal model of a critical discussion. The incremental approach starts from a simplified, basic dialogue game for restricted critical discussion, to which more elaborate or complex features can be gradually added. Characteristic of the current incarnation of the dialogue game, and the central issue in the paper, is the addition of the speech act perspective that is inherent in the pragma-dialectical discussion model. This perspective is accommodated in the dialogue game by basing the moves on the speech acts that are prototypically used to realise the discussion moves in the ideal model, and by using the fulfilment of the associated felicity conditions as the basis for commitments in the dialogue game. 
In Sect. 3, I laid down two more desiderata for the dialogue game formalisation of critical discussion. These had to do with maintaining strict turn-taking, and letting criticism target the full propositional content of argumentation instead of first decomposing potentially complex propositions. In both respects, the dialogue game for critical discussion seems to perform adequately. During each turn, a player may only make one move, after which the turn passes to the other player. Additionally, there can be no instance where one player has to take two turns in a row because the other player passes without making a move. Furthermore, when Ant casts doubt on the acceptability of the propositional content of the argumentation, the only way of doing this is by targeting the whole of the propositional content. Admittedly, this latter result is not of great value yet because of the current restriction to single argumentation. When complex argumentation structures, such as multiple or coordinatively compound argumentation, are introduced in the dialogue game, then this desideratum should be revisited.

By accounting for the speech act perspective of critical discussion, the dialogue game is brought one step closer to being a formalisation with the full scope of features of the ideal model. Further extensions to the dialogue game are obviously still required, several of which have been alluded to in Sect. 3 of this paper. In addition, the dialogue game has to be computationally implemented to test whether it indeed forms an adequate preparatory step for the computational application of the pragma-dialectical theory.

Acknowledgments I would like to thank the steering committee of the first European Conference on Argumentation (ECA) and the chair and members of the jury of the 2015 van Eemeren Prize for their encouragements. Additionally, I am grateful to my ECA commentator, Alice Toniolo, for her valuable comments and suggestions during the conference, to the two anonymous reviewers, and to Frans van Eemeren, Francisca Snoeck Henkemans and Bart Verheij for their advice.

Open Access This article is distributed under the terms of the Creative Commons Attribution 4.0 International License (http://creativecommons.org/licenses/by/4.0/), which permits unrestricted use, distribution, and reproduction in any medium, provided you give appropriate credit to the original author(s) and the source, provide a link to the Creative Commons license, and indicate if changes were made.

\section{References}

Austin, L.J. 1962. How to do things with words. Oxford: Clarendon Press.

Barth, E.M., and E.C.W. Krabbe. 1982. From axiom to dialogue: A philosophical study of logics and argumentation. Berlin: Walter de Gruyter.

Bex, F., J. Lawrence, M. Snaith, and C.A. Reed. 2013. Implementing the Argument Web. Communications of the ACM 56(10): 66-73.

Budzynska, K., M. Janier, J. Kang, C. Reed, P. Saint-Dizier, M. Stede, and O. Yaskorska. 2014. Towards argument mining from dialogue. In Computational models of argument, Proceedings of COMMA 2014, ed. S. Parsons, N. Oren, C. Reed, and F. Cerutti, 185-196. Amsterdam: IOS Press.

Dung, P.M. 1995. On the acceptability of arguments and its fundamental role in nonmonotonic reasoning, logic programming and n-person games. Artificial Intelligence 77(2): 321-357.

Garssen, B. 1997. Argumentatieschema's in pragma-dialectisch perspectief [Argument schemes in a pragma-dialectical perspective]. Amsterdam: IFOTT. 
Gordon, T.F. 2010. An overview of the Carneades argumentation support system. In Dialectics, dialogue and argumentation: An examination of Douglas Walton's theories of reasoning, ed. C.W. Tindale, and C. Reed, 145-156. London: College Publications.

Hamblin, C.L. 1970. Fallacies. London: Methuen.

Hamblin, C.L. 1971. Mathematical models of dialogue. Theoria 37: 130-155.

Houtlosser, P. 1995. Standpunten in een kritische discussie [Standpoints in a critical discussion]. Amsterdam: IFOTT.

Jackson, S. 1985. What can speech acts do for argumentation theory? In Argument and social practice, ed. J.R. Cox, M.O. Sillars, and G.B. Walker, 127-138. Annandale, VA: National Communication Association.

Jackson, S. 1992. 'Virtual standpoints' and the pragmatics of conversational argument. In Argumentation illuminated, ed. F.H. van Eemeren, R. Grootendorst, J.A. Blair, and C.A. Willard, 260-269. Amsterdam: Sic Sat.

Jacobs, S., and S. Jackson. 1982. Conversational argument: A discourse analytic approach. In Advances in argumentation theory and research, ed. J.R. Cox, and C.A. Willard, 205-237. Carbondale: Southern Illinois University Press.

Krabbe, E.C.W. 1982. Studies in dialogical logic. Doctoral dissertation, Groningen University.

Krabbe, E.C.W. 2006. Logic and games. In Considering pragma-dialectics: A festschrift for Frans H. van Eemeren on the occasion of his 60th birthday, ed. P. Houtlosser, and A. van Rees, 185-198. Mahwah, NJ: Lawrence Erlbaum.

Krabbe, E.C.W. 2012. Formal dialectic: From Aristotle to pragma-dialectics, and beyond. In Computational models of argument: Proceedings of COMMA 2012, ed. B. Verheij, S. Szeider, and S. Woltran. Amsterdam: IOS Press.

Krabbe, E.C.W. 2013. De formalisering van kritische discussie [The formalisation of critical discussion]. In Studies in taalbeheersing 4, ed. R. Boogaart, and H. Jansen, 233-243. Assen: Van Gorcum.

Krabbe, E.C.W., and D.N. Walton. 2011. Formal dialectical systems and their uses in the study of argumentation. In Keeping in touch with pragma-dialectics, ed. E. Feteris, B. Garssen, and F. Snoeck Henkemans, 245-263. Amsterdam: John Benjamins.

Levinson, S.C. 1983. Pragmatics. Cambridge: Cambridge University Press.

Lippi, M., and P. Torroni. 2016. Argumentation mining: State of the art and emerging trends. ACM Transactions on Internet Technology 16(2): 1-25.

Lorenzen, P., and K. Lorenz. 1978. Dialogische Logik [Dialogical logic]. Darmstadt: Wissenschaftliche Buchgesellschaft.

Mackenzie, J.D. 1979. Question-begging in non-cumulative systems. Journal of philosophical logic 8: 117-133.

McBurney, P., and S. Parsons. 2009. Dialogue games for agent argumentation. In Argumentation in artificial intelligence, ed. I. Rahwan, and G. Simari, 261-280. Dordrecht: Springer.

Norman, T.J., D.V. Carbogim, E.C.W. Krabbe, and D.N. Walton. 2004. Argument and multi-agent systems. In Argumentation machines: New frontiers in argument and computation, ed. C. Reed, and T.J. Norman, 15-54. Dordrecht: Kluwer.

Pollock, J. 1987. Defeasible reasoning. Cognitive Science 11: 481-518.

Prakken, H. 2009. Models of persuasion dialogue. In Argumentation in Artificial Intelligence, ed. I. Rahwan, and G. Simari, 281-300. Dordrecht: Springer.

Rahwan, I., and K. Larson. 2009. Argumentation and game theory. In Argumentation in artificial intelligence, ed. I. Rahwan, and G. Simari, 321-339. Dordrecht: Springer.

Rahwan, I., and G.R. Simari (eds.). 2009. Argumentation in artificial intelligence. Dordrecht: Springer.

Rescher, N. 1977. Dialectics. Albany, NY: State University of New York Press.

Scheuer, O., F. Loll, N. Pinkwart, and B.M. McLaren. 2010. Computer-supported argumentation: A review of the state of the art. International Journal of Computer-Supported Collaborative Learning 5(1): 43-102.

Searle, J.R. 1969. Speech acts: An essay in the philosophy of language. Cambridge: Cambridge University Press.

Tolchinsky, P., U. Cortés, and D. Grecu. 2008. Argumentation-based agents to increase human organ availability for transplant. In Agent technology and e-health, ed. R. Annicchiarico, U. Cortés, and C. Urdiales, 65-94. Basel: Birkhäuser.

van Eemeren, F.H. 2010. Strategic maneuvering in argumentative discourse: Extending the pragmadialectical theory of argumentation. Amsterdam: John Benjamins. 
van Eemeren, F.H. 2015a. Bingo! Promising developments in argumentation theory. In Proceedings of the 8th conference of the International Society for the Study of Argumentation (ISSA), 1-4 July 2014, ed. A.F. Snoeck Henkemans, B. Garssen, D. Godden and G. Mitchell. Amsterdam: Sic Sat.

van Eemeren, F.H. 2015b. Reasonableness and effectiveness in argumentative discourse: Fifty contributions to the development of pragma-dialectics. Cham: Springer.

van Eemeren, F.H., and R. Grootendorst. 1984. Speech acts in argumentative discussions: A theoretical model for the analysis of discussions directed towards solving conflicts of opinion. Dordrecht: Foris.

van Eemeren, F.H., and R. Grootendorst. 1989. Speech act conditions as tools for reconstructing argumentative discourse. Argumentation 3: 367-383.

van Eemeren, F.H., and R. Grootendorst. 1992. Argumentation, communication, and fallacies: A pragmadialectical perspective. Hillsdale, NJ: Lawrence Erlbaum.

van Eemeren, F.H., and R. Grootendorst. 2004. A systematic theory of argumentation: The pragmadialectical approach. Cambridge: Cambridge University Press.

van Eemeren, F.H., and T. Kruiger. 1985. Het identificeren van argumentatieschema's [The identification of argument schemes]. Forum der Letteren 26(4): 298-308.

van Eemeren, F.H., R. Grootendorst, S. Jackson, and S. Jacobs. 1993. Reconstructing argumentative discourse. Tuscaloosa, AL: The University of Alabama Press.

van Eemeren, F.H., P. Houtlosser, and A.F. Snoeck Henkemans. 2007. Argumentative indicators in discourse. A pragma-dialectical study. Dordrecht: Springer.

van Eemeren, F.H., B. Garssen, E.C.W. Krabbe, A.F. Snoeck Henkemans, B. Verheij, and J.H.M. Wagemans. 2014. Handbook of argumentation theory. Amsterdam: Springer.

Verheij, B. 2005. Virtual arguments: On the design of argument assistants for lawyers and other arguers. Den Haag: Asser.

Visser, J.C. 2013. A formal account of complex argumentation in a critical discussion. In Virtues of argumentation. Proceedings of the 10th international conference of the Ontario Society for the Study of Argumentation (OSSA), 22-26 May 2013, ed. D. Mohammed and M. Lewiński, 1-14. Windsor, ON: OSSA.

Visser, J.C. 2015a. A formal perspective on the pragma-dialectical discussion model. In Proceedings of the 8th conference of the International Society for the Study of Argumentation (ISSA), 1-4 July 2014, ed. A.F. Snoeck Henkemans, B. Garssen, D. Godden and G. Mitchell. Amsterdam: Sic Sat.

Visser, J.C. 2015b. Het formaliseren van kritische discussie ter voorbereiding op geautomatiseerde argumentatieanalyse [The formalisation of critical discussion in preparation of automated argumentation analysis]. Tijdschrift voor Taalbeheersing 37(3): 321-349.

Visser, J.C. 2016. Speech acts in a dialogue game for critical discussion. In Argumentation and reasoned action. Proceedings of the first European conference on argumentation, 9-12 June 2015, ed. D. Mohammed and M. Lewiński. London: College Publications.

Walton, D.N., and E.C.W. Krabbe. 1995. Commitment in dialogue: Basic concepts of interpersonal reasoning. Albany, NY: SUNY Press.

Wittgenstein, L. 1953. Philosophische Untersuchungen [Philosophical investigations]. Malden, MA: Blackwell.

Woods, J., and D.N. Walton. 1978. Arresting circles in formal dialogues. Journal of philosophical logic 7: 73-90. 